\title{
The Impact of Human Resources Management Practices on Job Satisfaction among Telecommunication Firms in Jordan
}

\author{
Abdelmoutaleb Mohammad Alamri
}

\begin{abstract}
job satisfaction has become the target of many organizations which sought to achieve it through various practices to motivate the employee and give the best in their jobs. The major purpose of this research is to examine the impact of human resource management HRM practices on job satisfaction in Jordanian telecommunication firms. The data used in this study were collected through a survey questionnaire was designed and adapted to fit the scope of the study and measuring the variables involving in this work to provide new valued insights from 223 samples from three different telecommunication firms operating in Jordan named Orange, Umniah and Zain. This sector has an essential contribution to this sector in the national economy and foreign investment. The results showed a positive impact of HRM practices on job satisfaction which consists of three constructs in this research name workplace environment; incentives and rewards; and job security. The findings were consistent with some studies and found a significant effect of the different activities of HRM on job satisfaction. The research also provides several helpful implications for practitioners and academicians to make new studies and filling the existed research gap by examining new variables handles contemporary issues and providing innovative business solutions.
\end{abstract}

Keywords: human resource management; job satisfaction; telecommunication firms; Jordan.

DOI: $10.7176 / \mathrm{EJBM} / 12-17-02$

Publication date:June 30th 2020

\section{Introduction}

The Jordanian telecommunication sector has evidence a large rate of economic growth over the last few years and the total assets of Jordanian telecommunication which Jordan is one of the fast-growing telecommunication markets in the region. This development has changed Jordan's economy also its image from a slow-growing low technology economy to a high-desired market of new innovative investors. The competitiveness of this sector has reached revenue of $\$ 681,710,762$ in 2017 and the IT services industry also continues in developing and stabilizing the national economy (Hamdoun et al., 2016). This sector has progressed over the last few decades with major concerns of IT facilities, technological infrastructure, and software development as well as sales of mobile and internet services providers. According to the studies that collected data and analyzed from many companies currently working in Jordan, the telecommunication and IT sector industry contributed largely to the export which the revenues have reached hundreds of millions in domestic revenues. Therefore, this sector has become among worldwide leaders in the IT industry and telecommunication services, and the exports of these products not only spread locally but also globally. Many studies confirmed the importance of human resource management HRM and considered as a major influencer and determinants of developing an organizational competitive advantage, and the whole success or failure in any business (Poór et al., 2015). The field of HRM is primarily vital especially in services industry companies and businesses compared with the manufacturing sector because of the diverse service features such as intangibility. These service features have indications of services organizations in terms of managing the operations and implementation of marketing activities.

as it were Jordanian business management is a mix of values earned from western and eastern culture and these values constantly changing. Particular researches presently revealed that compared with the previous values of Jordan people intend to be less collectivistic and hierarchical as well as less risk-averse (Obeidat et al., 2016). These societal and values rapid changes might have important implications for HRM activities in Jordan. Although the attempts to explore the relationship between the various number of HRM practices and employees' attitudes which some of them indicated a positive and direct relationship between them, they still limited in a particular setting and ways of the methodology used to conduct like these studies. Present HRM surveys which explore the impact of HRM activities on employee attitudes such as job satisfaction do not adequately contextualize their research associated with specific factor linked to the workplace environment. Therefore, there is a high need to study these activities and the possible implications of job outcomes like employee satisfaction. the interest of studying the factors influencing satisfaction of the employee in the workplace still attracting more attention and concern of many scholars in different fields and contexts which indicates the essential and vitality of this business issue in the current high intense competitive business environment. Based on the above rationale this study investigates the effect of HRM practices on job satisfaction as the factor of satisfaction may support and lead to greater levels of performance, commitment, and productivity.

\section{Literature Review}

The HRM concept backs of the human facet of the management and organizations as well workforces interrelations 
with their management and it aims to assure that the employees of organizations are sufficiently and effectively used in a method with ensure obtaining great benefits of these workforces from their capabilities, they attain their rewards either financially or psychological from the services they provided. The current businesses highly depend on the dynamic HRM to make sure that they select, recruit, develop and train talent and skilled staff who can respond to the employees' complaints in order to achieve levels of satisfaction towards their jobs (Baumgärtner et al., 2015). The professional in the field of HRM states both numbers and types of the employees which any organization should have to survive and operate well in the business environment also accomplish their goals especially in the first years of its life. Also, their several responsibilities include hiring and recruiting the employees to fill or replace the vacant positions that newly created. A department of HRM engages also in developing and training its workforces to enhance their staff's job satisfaction ( $\mathrm{Lu}$ et al., 2016). In the same vein, HRM practitioners execute and manage rewords systems and compensation policy also the benefit package of the employees. Generally, this feature has been debated to be the main part of the essential matters associated with work satisfaction, if not effectively and adequately handled. However, HRM could be identified as a set of interrelated functions that ideological and philosophical connected and they underpin with their designed plans to classify the major human resources aspects such as recognizing the belief and assumption and taking the strategic decisions about people management (Arifin, H.M., 2015).

There are many discussions related to HRM functions which categorized under different main fields: (1) job analysis and design (2) recruitment (3) performance management evaluation (4) employment training and development; and (5) rewards and compensation system, motivation and controlling (Paşaoğlu, 2015). The whole major purpose of HRM is to ensure the ability of the company to accomplish long-term organizational success through workforces. As existed in the relevant literature, researchers have argued that HRM plans can be the core of organizational resources which permits the companies to create and build up based on the available opportunities. However, as presented in the HRM literature, it seems to be interrelated with implementing many functions for instance related to the organizational effectiveness, human capital management; talent management; benefits management; work interrelations, and fulfilling numerous demands (Armstrong, 2020). Basically, achieving high levels of job satisfaction is related to greater productivity, fewer rates of turnover, and absenteeism. Many studies which examine the impact of several factors on job satisfaction among different sample in different context reported that low levels of commitment for example or employees' productivity are directly related to the levels of job satisfaction, which were less than the desired expectation. Furthermore, the same studies also evidenced that sample showed their willingness and readiness to quit current work and change the job once get a new satisfied opportunity; therefore it is confirmed that job satisfaction has a great role and plays a support factor in employee' attitudes and their decisions to change the work (Abubakar et al., 2015). Emphasis on job satisfaction should be placed on the employers' goals regarding employee's great performance and it is important to put it to the belief that job satisfaction is a function of job and organization performance. With this perception, the current study proceeds further to explore and discuss the concept of job satisfaction.

The scholars in the area of job satisfaction have defined it from different points of view and ways. It is defined as a collection of both cognitive and affective responses to the distinctive understanding and perceptions of what the employee needs to get compared to what gets (Thiagaraj and Thangaswamy, 2017). Similarly, job satisfaction is perceived as an individual's cognitive, affective, and assess the attitudes towards the job. Therefore, it can be also defined as a state where the worker's needs and outcomes consistent well. The concept of job satisfaction is debated to be responding emotionally to the individual's job. As an idea, job satisfaction could be explained merely in monetary shape. It also has been discussed that the staff generally respect the rewards and on the other hand dislike the duties. Therefore, a greater salary for the same level of duties surely will decide to leave the job that has lower benefits that would increase the feeling of satisfaction (Judge et al., 2017). Mostly, there is a need to view the employment needs beyond the match of services with provided salaries. Even though the employment needs are seen as economic benefits in nature, but it is fundamental to see that it has a great connection to the socioeconomic view. It can see a stratified employee with adequate monetary benefits and rewards to express some level of dissatisfaction with some features of his employment expectations like management plans, due to they act as an obstacle in order to achieve these needs or demands or because the expectations are not achieved by the financial benefits (Mabaso and Dlamini, 2017).

A view emphasized at the resource-based view developed by Wright and Snell (2001) that focuses on attaining sustainable competitive advantage for organizations through various approaches and effective means should be used to manage sufficiently the available resources of the organizations. The theory of Resource-based has made some changes in the many fields of management such as the strategic management perspective and change the thinking way from outside-in pattern to an inside-out pattern of management (Barney, 2017). However, the wide usage of this paradigm compared to the old theory allow the organizations to arrange their internal resources in a way to achieve their organizational success starting from determining the approach of thinking and change it based on the contemporary paradigms associated with the human resources. This theory has applied among many scholars specifically in the area of HRM and indicates that the employees hold values, skills, and 
attitudes that based on some theorists Barney (2017) considered essential requirements of organizational success. The rationale of selecting the resource-based view in this work gives the scholars different benefits in exploring and examining some factors of the strategic HRM with linking to other variables. The variable of satisfaction has been featured with variability which rated over many attempts have made to study them. The situational perspective of the factor satisfaction shows a variety due to the study conditions variations. On the other view, the dispositional perspective notes the satisfaction also varies because of the affective disposition difference. Hertzberg's theory called Two-Factor Theory suggests that job content factors like responsibility, perception, work nature, achievement, and development are major factors either increasing or decreasing the levels of satisfaction among works. Furthermore, some factors play a role in enhancing the rate of satisfaction among the employees also responsible for lack or broaden the job satisfaction, for example, salary, working environment conditions, organization structure, management, compensation and reward systems, job security and staffs interrelations (Armstrong and Taylor, 2020). A model of satisfaction belonging of Lawler named Equity-based model described the satisfaction as a process of comparison between the perceived attitudes toward the job and the extent they match with the desired perception. The theory indicates that satisfaction is also a function of the extent the individual's job is recognized as fulfilling vital beliefs and values perceived and associated with the job features consistent with wanted and desired features. In addition, satisfaction is stated through the differences between desirable conditions of the job factors (salary, independence, etc.) and the real conditions (Tao et al., 2015).

As a modern concept, the workplace environment has been studied many in different studies over various businesses to examine its effect with another critical construct like job satisfaction. The factor of the work environment has linked also with the intent of employees to stay at their jobs due to its significance in creating a greater level of satisfaction among workers (Agbozo et al., 2017). In developing states, for example, numerous studies have tested and discussed the positive relationships between the employees' impression of the work environment and the outcomes of job satisfaction and loyalty. For instance, a significant effect and assessments of the resources adequacy and higher levels of management support a healthy work environment which will lead to creating a positive commitment among staff which in turn increases the rates of satisfaction and minimize their willingness to leave their jobs. In Chen and Fang (2016) research, they examined the relationships between work environment of nursing and the influence on turnover rates, job satisfaction also burnout of jobs in a cross-sectional study including 1,113 registered nurses working in more than 80 medical, clinical, and intensive care units in more than 19 hospitals over the city of Mainland in China. The findings demonstrated the inverse relationships between the workplace setting and nurses' satisfaction and the level of job-related burnout. In the same vein, a study showed that the work environment of nursing had a great impact on the performance and it recommended supporting this result and providing more continuous evaluation and systematic monitoring of the employees' work environment should be considered. These results propose that statues of the workplace could alter across time and are could help for improvement (Sveinsdóttir et al., 2016).

Furthermore, the factor of incentive and reward has obtained much concern in the current academic studies and attracts the interests of the management professionals also scholars in the business area. Generally, over the world in several contexts and industries, the incentives and rewards with linking some of the crucial constructs were provided critical implications and research paths which motivate the future studies to focus on new phenomena and emerging issues in the human resources management and analyze them as a motivational technique for better performance employee (Benslimane and Khalifa, 2016). These incentives and rewards are analyzed in different forms which may take a financial form or non- financial benefits for particular expected behaviors. The most common description of incentive and reward is something that is got or earns as a result of achieving success or progress. In other words, these factors are used as an estimation of outstanding achievement or remarkable behaviour which could be monetary or non-monetary rewards after this success (Al-Belushi and Khan, 2017). The reward is the appreciation that granted to the individuals for being an estimated and valued person in the company. Moreover, job security is defined as the chances of having individuals their jobs. Usually, the concept of job insecurity is measured through multiple indications that confirm the probability to lose a job or the lack of job security in most business settings which also defined as become again unemployed (Wilczyńska et al., 2016). A systematic review of the topic of job insecurity associated with many factors and the extent of how they are related, there is a growth of interest aim to examine this concept over the last decades and they suggest that the concept of job security should contextualize through multidimensional variables instead of universal measurements. The various methods have analyzed with job insecurity as well as examine several constructs as an element of this concept. The general determinants of job security are two elements: the threat of loss of the job and the opportunities that could be provided once individuals lose the job (Sender et al., 2017). The most theoretical models discussed the variable of job security and distinguished between the probability of the possible threats of losing the job and the pressures to accept less secured jobs and they suggested enforcing safe conditions among the business environment and offer a secured atmosphere to enable the employee work safely. Based on the above literature, the current study hypothesized the following research hypotheses as follow:

H1: There is a positive impact of HRM practices on job satisfaction in telecommunication firms in Jordan. There 
are sub hypotheses under this main hypothesis as follow:

H1a: There is a positive impact of workplace environment on job satisfaction in telecommunication firms in Jordan. H1b: There is a positive impact on incentives and rewards on job satisfaction in telecommunication firms in Jordan. H1c: There is a positive impact of job security on job satisfaction in telecommunication firms in Jordan.

\section{Research Methodology}

This work has been carried out through both a descriptive and quantitative approach design which concentrating on the important impact of HRM activities practiced in the telecommunication firms in Jordan. However, the author collected the relevant data link with the main scope of this research. It is recommended using both secondary and primary data which add more reliable and valid material and resources to the research and provide a wide range and variety of insights and ideas (Creswell and Creswell, 2017). The primary data is defined as the data were collected by designing an instrument including the variable being studied and send to the intended sample to measure their agreeable or not of some statements and factors, meanwhile the secondary data are the already existed materials over different sources like databases or universities theses which also support the research in achieving its objectives and compare its results with the related similar studies (Mohajan, 2018). The scholars in the method part of the study outlined the study design and the methodological as well the techniques used in determining and choosing the ultimate sample also the statistical analysis determined to test the research hypotheses and how the instrument is reliable to conduct the study. This study has developed an instrument which includes set of items have designed to measure the concepts of the study, it is adapted from previous related studies which examine the same concepts but in different contexts and sample but they could be used in this study with some modifications to fit the nature of current research. A prior to conducting the study, the researcher firstly validates the questionnaire by sending it to a panel of experts in the field of the study as well as academicians who have experience in validating the survey questionnaire to get their feedback and make if necessary any correction or additions. Regarding the sampling technique used in this study, a random sample method was used which is mostly desired in the business research in order to avoid any bias and achieve the objectivity of results, this method gives all objects in the population the same chance to be selected over the analysis. The unit analysis of this study is the employees working in the three different telecommunication firms in Jordan (Orange, Zain, and Umniah) with managerial levels.

A total of (223) sample from different departments were randomly chosen to well represent the targeted population of this work which designed with a Five Likert measure which is considered most preferred in measuring the responses of the sample, they ranked from strongly disagree to strongly agree of the provided statements and they give a weight for statistical consideration. The greater of the mean indicates a valid response of agreeing with the items. To easy handle with the questionnaire, it was separated into different parts which include demographic data part which asks the respondents their age, gender, education level, experience years, the second part includes the statements of each factor to gauge the constructs identified in the research which also was separated into sub-constructs like the variable of HRM hold three of the sub-constructs name workplace environment, incentive, and rewards and job security. The rationale of selecting those factors, the little examination they received among the existed literature, and the research gaps found in terms of examining the concept of job satisfaction whereas most of the studies focus on mature constructs (Bakotić, 2016). The job satisfaction variable has been measured through 8 items, on the other hand, the HRM variable has three sub-variables each measured by 4 items. As a prior needed process to check the reliability of the study's survey, a Cronbach alpha test was conducted to see how the items associated with their factor, the cut off of minim values of this test was 0.7 based on the statisticians which also some of them suggest 0.6 could be the accepted lower value of Cronbach alpha analysis (Taber, 2018). Table 1 shows the results of this test which most of the values exceeded the minimum value which confirms the ability of these items in measuring their factors.

Table 1: Study Reliability

\begin{tabular}{|l|l|l|}
\hline Variable name & No of items & Cronbachalpha \\
\hline Job satisfaction & 8 & 0.922 \\
\hline HRM factors & \multicolumn{2}{|l|}{} \\
\hline Workplace environment & 4 & 0.819 \\
\hline Incentives and rewards & 4 & 0.822 \\
\hline Job security & 4 & 0.653 \\
\hline
\end{tabular}

\section{Research Results and Discussion}

After collecting the data through the questionnaire, in this section the discussion of the results was analyzed to extract the main findings, as the stud is a descriptive approach, it is important to describe the data obtained and the percentage of demographic data. In addition, in this part, we test the hypotheses by explaining the results and interpreting the information. Table 2 presents the demographic description of the study sample which consisted of (223) of different managerial levels of the employees from both genders and various experiences and educational 
levels.

Table 2. Characteristic of the Respondents $(n=223)$

\begin{tabular}{|l|l|l|}
\hline Variable & \multicolumn{2}{|l|}{ Frequency percentage } \\
\hline Gender & 132 & 59.2 \\
\hline Male & 91 & 40.8 \\
\hline Female & 223 & \\
\hline Total & \multicolumn{2}{|l|}{} \\
\hline Experience & 35 & 15.7 \\
\hline$<5$ years & 61 & 27.4 \\
\hline 6-10 years & 81 & 36.3 \\
\hline $11-15$ years & 46 & 20.6 \\
\hline$>15$ years & 223 & \\
\hline Total & \multicolumn{2}{|l|}{} \\
\hline Educational levels & 72 & 32.3 \\
\hline Secondary level & 119 & 53.4 \\
\hline Bachelor & 27 & 12.1 \\
\hline Master & 5 & 2.2 \\
\hline Ph.D & \multicolumn{2}{|l}{} \\
\hline Job title & 19 & 8.5 \\
\hline Technician & 110 & 49.3 \\
\hline Junior level & 82 & 36.8 \\
\hline Senior level & 12 & 5.4 \\
\hline Manager & 223 & \\
\hline Total &
\end{tabular}

Analyzing the characteristics of the participants as shown in (Table 2), the most of them were generally male $(59.2 \%)$ which this outcome can be explained the majority of the staff working in the telecommunication firms in Jordan were male which indicate the nature of some positions in these firms require good physical health like those technicians which needs to make maintenance of the technical issues could happen in the networks of the firms whereas the most of administrative positions were female and no need for a large effort which both genders can do these tasks. However, the highest percentage of experiences of the participants was $36.6 \%$ for the experience between 11-15 years which indicates the most participants have great experiences and the rates of turnover are lower which could also indicate greater levels of job satisfaction. in terms of education levels, the most of sample were bachelor holder with around 53.4\%, 12.1 master and 2.2\% Ph.D. holders which indicated a wide variety of educational levels for the sample involved in this research which also demonstrated the workforces working in the telecommunication firms should hold higher education levels because of the importance of this industry which contribute highly in the national economy and provide more new products which have become essential among the globalization and industrialization outcomes. This part tests the identified hypotheses which focus on the impact of HRM on job satisfaction. Simple linear regression is the most common statistical used to examine the effect among different variables. The outcomes either reject or accept the hypothesis based on some statistic criteria and values in which the rule in these terms is accepting the null hypothesis if the significance level is equal or less than 0.05 and reject it if it is higher than this value.

H1: There is a positive impact of HRM practices on job satisfaction in telecommunication firms in Jordan. The linear regression was conducted to test this hypothesis and the statistical results are shown in Table 3.

Table 3 Overall HRM Practices on job satisfaction

\begin{tabular}{|l|l|l|l|l|l|l|l|l|}
\hline Hypothesis & $\mathrm{R}$ & $\mathrm{R}^{2}$ & $\mathrm{df}$ & $\mathrm{f}$ & beta & $\mathrm{t}$ & Sig. & Decision \\
\hline H1 & 0.864 & 0.747 & 221 & 652.688 & 0.864 & 25.548 & 0.000 & Accept \\
\hline
\end{tabular}

Table (3) indicates that overall HRM practices positively impact effect on the job satisfaction construct. The value of R2 is $(0.747)$, which indicates that overall HRM practices explain $(74.7 \%)$ of the variance of job satisfaction. The greater value of $\mathrm{R}(0.864)$ showed that the study conceptual framework has a significant impact. So that, the null hypothesis is rejected, and the alternative hypothesis indicates a positive impact of HRM practices on job satisfaction which confirms the vital role of several HRM activities in achieving greater levels of job satisfaction among telecommunication firms in Jordan. The surveyed firms' management largely gives more attention to the various HRM activities to sustain a great feeling of satisfaction among their employees which in turn will maintain the retention rates of workforces and reduce their turnover rates. The results revealed general impact and support for the HRM framework which consisting of three factors and confirmed the previous related publication similar to those factors in different contexts. The researcher attributes this mixture of HRM activities to telecommunication unique business setting context which consistent with studies (Jyoti et al., 2017). Our study supports this perspective and suggests that telecommunication firms could contribute to job satisfaction because 
of the large concern of their employee's impressions and commitment. The current HRM practices probably are linked and supportive with many factors also with each other, explaining that in the employee relationships model, HRM models contribute to broadening the employee job satisfaction and their willingness to stay beyond these telecommunication firms which emphasize the significance of being satisfied.

H1a: There is a positive impact of workplace environment on job satisfaction in telecommunication firms in Jordan. The linear regression was conducted to test this hypothesis and the statistical results are shown in Table 4.

Table 4. Workplace Environment on Job Satisfaction

\begin{tabular}{|l|l|l|l|l|l|l|l|l|}
\hline Hypothesis & $\mathrm{R}$ & $\mathrm{R}^{2}$ & $\mathrm{df}$ & $\mathrm{F}$ & Beta & $\mathrm{t}$ & Sig. & Decision \\
\hline H1a & 0.849 & 0.720 & 221 & 568.779 & 0.849 & 23.849 & 0.000 & Accept \\
\hline
\end{tabular}

Table 4 shows that the effect size of the workplace environment and the variation value explained the variable job satisfaction of the variation in the workplace environment was $(72 \%)$, the $F$ value is (568.779), and the significance level is (0.000). Since the significance level is less than (0.05), the study rejects the null hypothesis and accepts the alternative hypothesis which states: There is a positive impact of workplace environment on job satisfaction at Jordanian telecommunication firms. The interpretation of this result may be explained in terms of the effective role of workplace environment in creating job satisfaction which indicates also the significance of this factor in linking with job satisfaction and match with the recent increasing demand for effective HRM. Dharmanegara et al. (2016) as well proposed that providing more attractive aspects among workplace settings surely supports the employees to get a clear orientation which increases their productivity and they become more creative. Providing the employees with a typical workplace considering different aspects of spirituality for example or physical facilities also support in creating a superior intercommunication. Enhancing communication within the workplace and staff could establish better honesty and deep trust between them. This also could help the individual accept the overloading of their work and ignore the problems which should reflect on a greater performance of their tasks. This could also confirm that involving the employee amongst the decision and allow them to participate in the decisions belonging to them would assist in encouraging them to achieve better.

$\mathrm{H} 1 \mathrm{~b}$ : There is a positive impact on incentives and rewards on job satisfaction in telecommunication firms in Jordan. The linear regression was conducted to test this hypothesis and the statistical results are shown in Table 5.

Table 5. Incentives and Rewards on Job Satisfaction

\begin{tabular}{|l|l|l|l|l|l|l|l|l|}
\hline Hypothesis & $\mathrm{R}$ & $\mathrm{R}^{2}$ & $\mathrm{df}$ & $\mathrm{F}$ & Beta & $\mathrm{t}$ & Sig. & Decision \\
\hline H1b & 0.716 & 0.513 & 221 & 232.653 & 0.716 & 15.253 & 0.000 & Accept \\
\hline
\end{tabular}

Table 5 shows that the effect size of incentives and rewards and the variation value explained the variable job satisfaction of the variation in incentives and rewards were $(51 \%)$, the F value is $(232.653)$, and the significance level is (0.000). Since the significance level is less than (0.05), the study rejects the null hypothesis and accepts the alternative hypothesis which states: There is a positive impact of incentives and rewards on job satisfaction at Jordanian telecommunication firms. The interpretation of this outcome could be explained in terms of the remarkable influence of incentives and rewards in creating job satisfaction which indicates also the pivotal role of this construct in connecting with the job satisfaction and agree with the perspectives of focus on reward systems to make the employees satisfied. Despite this result may look different than workers are less satisfied with fewer rewards job and that pay less, this finding is repeated with other papers (Carbonell and Rodríguez-Escudero, 2016) that have found that the effects of rewards depending on the magnitude and type of incentive and rewards as well the performance which could be either negative or positive effect. Therefore, the rewards and monetary incentives are beneficial to create large levels of satisfaction and commitment among the employees which will reflect on service or product quality and motivate them to focus on the whole firm's goals and make the vision become true. In terms of the joint impact, the results suggest that telecommunication firms should integrate the rewards systems within their retention strategy to avoid lower levels of employees' performance and job quality.

H1c: There is a positive impact of job security on job satisfaction in telecommunication firms in Jordan. The linear regression was conducted to test this hypothesis and the statistical results are shown in Table 6.

\begin{tabular}{|c|c|c|c|c|c|c|c|c|}
\hline Hypothesis & $\mathrm{R}$ & $\mathrm{R}^{2}$ & $\mathrm{df}$ & $\mathrm{F}$ & Beta & t & Sig. & Decision \\
\hline H1c & 0.575 & 0.331 & 221 & 109.106 & 0.575 & 10.445 & 0.000 & Accept \\
\hline
\end{tabular}

Table 6 shows that the effect size of job security and the variation value explained the variable job satisfaction of the variation in job security was (33\%), the F value is (109.106), and the significance level is $(0.000)$. Since the significance level is less than (0.05), the study rejects the null hypothesis and accepts the alternative hypothesis which states: There is a positive impact of job security on job satisfaction at Jordanian telecommunication firms. The interpretation of this result also indicates the great effect of job security in providing and enlarging the willingness to stay with the current job and leave the intent to quit whereas this factor represents the genuine need for the employees to whether decide to continue with an unsecured job environment or seek another safe one. Several empirical studies have proved this insight through examining the effect of employment stability on job satisfaction which mostly showed a positive effect. The factor of job security, often measured by the nature of the signed contract between the owner/management and the workers which state the type of their relationship and the 
main responsibility and duties as well other job aspects (Wilczyńska et al., 2016) which replicate with this study finding that assumed the individuals may be influenced directly their job satisfaction by the level of stability and security felt within the workplace setting. As well through the effects on other similar factors, job security looks to give the workforces a feeling of security through flexible contracts that determining both the rights and duties between the contractors which were confirmed positive effects on job satisfaction. Interestingly, the implication of less employment flexibility will influence not only the existing groups of workers but also extend to the future potential candidates once they know the higher rates of turnover between employees because of the instability of job conditions. Thus, it is generally essential to offer standards and job security situations to the individuals in the organizations.

\section{Conclusion}

The research examined the impact of the HRM practices on job satisfaction among telecommunication firms in Jordan. The major objective of this study was to shed light on the role of various functions of HRM and their effectiveness to achieve higher levels of satisfaction of the employees, regardless those functions are managerial or combined two-way function. Furthermore, the current work also proved a statistically significant impact of the different identified HRM activities according to the different participants' levels towards their perception of job satisfaction. the study concluded that the effect of several HRM practices on job satisfaction was at the significant level, therefore, the results provided were considered as the questionnaire method that used to achieve objectives of the study, also it offered a remarkable result to the related studies in the same field due to the expected various opinions of the sample as well as the organizational structure existed in the selected population which being surveyed (telecommunication firms in Jordan). Moreover, the study also presented whether any effect existed between HRM practices and job satisfaction construct of the business organizations. The analysis confirmed all hypotheses were supported that telecommunication firms in Jordan are perceived the significant effect of different HRM practices on job satisfaction.

The research also has provided various theoretical contributions and it adds to already current material and literature on both job satisfaction and HRM through validating the HRM integrated constructs that can be utilized by scholars and professionals in the future study. The current paper is also contributing to the previous attempts by providing a great back for the effect of HRM on the factor of job satisfaction. In addition, it has empirically offered a deep discussion of sub-variables of HRM practices that confirmed in prior studies their effects to many constructs. Theoretically, our results implied that job satisfaction acts as an antecedent of other significant variables associated with the organizational performance such as commitment and loyalty of the employees which influence different elements that could support the whole target of the organizations. The research has also evaluated the HRM dimensions wisely and suggest involve a mediating effect of a new variable in the relationship between HRM activities and job satisfaction. All the dimensions of HRM, namely, workplace environment, incentives and rewards, and job security proved directly their significance to the variable of job satisfaction without any mediation effect. This paper's results are not contradictory to the previous studies which they confirm this effect and few of these studies showed negative findings of their variables. Besides this paper didn't propose any mediator or moderator between HRM activities and job satisfaction because of the wide belief the direct effect of those activities on job satisfaction. The last but not the least, this study offers new perspectives to the impact of HRM activities and job satisfaction by creating empirically a new conceptual framework in a more important industry in Jordan which is telecommunication firms that support the economy of Jordan. This paper has also numerous implications that are outstanding for academic bodies as well as business experts. These issues were discussed as under the aim to cope with the emerging contemporary concepts in the business field and human relationship in accordance with the dimension of organizational developments and performance in the telecommunication sector, job security relating to job satisfaction should be considered to the staff on a periodical basis evaluation and need to be modified effectively based on the changes over the businesses. This consideration may lead to a great workforce's performance by minimizing the rates of complaints which reflect in turn on the improvement of productivity.

Empirically, this paper assessed three HRM practices and their possible effect on their satisfaction levels and how these practices influence their desired intention to leave or stay with their present jobs. Regarding the outcomes and wide interests of present studies, the three identified factors of HRM activities like incentives and rewards was described as the best practice to the employee job satisfaction and this significance was emanated from the linking made by the employee between their monetary satisfaction and the actual incentive granted to them. The key practical implications of this paper are to support the management executives in concentrating more on the available HRM functions. Finally, the research results could provide a guideline for future researches about what is important to get a good performance and commitment of employees. In terms of the limitations, the study was limited to the scope of the research which only examines predetermined factors in a particular context with a certain sample. Most of these could limit the results which could not be generalized to other settings or sample but need to reconsider these issues while conducting future studies in the same area, thus the researcher suggests to 
integrate more new variables with different research methods and analysis to cover as much as of found research gaps also handles the critical and limited results were found in some related studies. Briefly, our work is not free of any type of limitation. Firstly, since the telecommunication sector was decided that the study community would be in Jordan, we recommend focusing on the greater levels of the managers and executives to collect the data. Hence, the sample should be randomly selected in the survey to minimize the bias rates in this work. Second, despite targeted data were collected from different employees working in telecommunication firms in Jordan, our analysis and findings are stuck with only one service sector in the telecommunication industry. In addition, the telecommunication firms involved in this research were varied in the nature and types of workplace environment and incentive as well rewards which will represent different responses among the sample. By investigating only telecommunication operated in one context under different brands, it is not clear whether the outcomes of the paper can be applied over different service industries. Therefore, future research intentions should combine new kinds of the service sector in its respective setting design as the relationship differs from one setting to another.

\section{References}

1. Abubakar, R.A., Chauhan, A. and Kura, K.M., 2015. Relationship between human resource management practices and employee's turnover intention among registered nurses in Nigerian public hospitals: the mediating role of organisational trust. SainsHumanika, 5(2).

2. Agbozo, G.K., Owusu, I.S., Hoedoafia, M.A. and Atakorah, Y.B., 2017. The effect of work environment on job satisfaction: Evidence from the banking sector in Ghana. Journal of Human Resource Management, 5(1), p.12.

3. Al-Belushi, F. and Khan, F.R., 2017. Impact of monetary incentives on employee's motivation: Shinas college of technology, oman-a case study. International Journal of Management, Innovation \& Entrepreneurial Research EISSN, pp.2395-7662.

4. Arifin, H.M., 2015. The Influence of Competence, Motivation, and Organisational Culture to High School Teacher Job Satisfaction and Performance. International Education Studies, 8(1), pp.38-45.

5. Armstrong, M. and Taylor, S., 2020. Armstrong's handbook of human resource management practice. Kogan Page Publishers.

6. Bakotić, D., 2016. Relationship between job satisfaction and organisational performance. Economic researchEkonomskaistraživanja, 29(1), pp.118-130.

7. Barney, J.B., 2017. The evolutionary roots of resource-based theory. The SMS Blackwell Handbook of Organizational Capabilities, pp.269-271.

8. Baumgärtner, M.K., Dwertmann, D.J., Boehm, S.A. and Bruch, H., 2015. Job satisfaction of employees with disabilities: The role of perceived structural flexibility. Human Resource Management, 54(2), pp.323-343.

9. Benslimane, N. and Khalifa, M., 2016, July. Evaluating Pharmacists' Motivation and Job Satisfaction Factors in Saudi Hospitals. In ICIMTH (pp. 201-204).

10. Carbonell, P. and Rodríguez-Escudero, A.I., 2016. The individual and joint effects of process control and process-based rewards on new product performance and job satisfaction. BRQ Business Research Quarterly, 19(1), pp.26-39.

11. Chen, Y.M. and Fang, J.B., 2016. Correlation between nursing work environment and nurse burnout, job satisfaction, and turnover intention in the western region of mainland China. Hu Li ZaZhi, 63(1), p.87.

12. Creswell, J.W. and Creswell, J.D., 2017. Research design: Qualitative, quantitative, and mixed methods approaches. Sage publications.

13. Dharmanegara, I.B.A., Sitiari, N.W. and Wirayudha, I.D.G.N., 2016. Job competency and work environment: the effect on job satisfaction and job performance among SME's worker. IOSR Journal of Journal of Business and Management (IOSRJBM) Volume, 18, pp.19-26.

14. Hamdoun, H., Alzubi, J.A., Alzubi, O.A. and Mangeni, S., 2016. Key Economic and Environmental Perspectives on Sustainability in the ICT Sector. arXiv preprint arXiv:1602.05559.

15. Judge, T.A., Weiss, H.M., Kammeyer-Mueller, J.D. and Hulin, C.L., 2017. Job attitudes, job satisfaction, and job affect: A century of continuity and of change. Journal of Applied Psychology, 102(3), p.356.

16. Jyoti, J., Chahal, H. and Rani, A., 2017. Role of Organizational Learning and Innovation in between Highperformance HR Practices and Business Performance: A Study of Telecommunication Sector. Vision, 21(3), pp.259-273.

17. Lu, L., Lu, A.C.C., Gursoy, D. and Neale, N.R., 2016. Work engagement, job satisfaction, and turnover intentions. International Journal of Contemporary Hospitality Management.

18. Mabaso, C.M. and Dlamini, B.I., 2017. Impact of compensation and benefits on job satisfaction. Research Journal of Business Management, 11(2), pp.80-90.

19. Mohajan, H.K., 2018. Qualitative research methodology in social sciences and related subjects. Journal of Economic Development, Environment and People, 7(1), pp.23-48.

20. Obeidat, B.Y., Al-Sarayrah, S., Tarhini, A., Al-Dmour, R.H., Al-Salti, Z. and Sweis, R., 2016. Cultural 
influence on strategic human resource management practices: A Jordanian case study. International Business Research, 9(10), pp.94-114.

21. Paşaoğlu, D., 2015. Analysis of the relationship between human resources management practices and organizational commitment from a strategic perspective: Findings from the banking industry. Procedia-Social and Behavioral Sciences, 207, pp.315-324.

22. Poór, J., Slavic, A. and Berber, N., 2015. The competences of HR managers and their impact on the organizational success of MNCs' subsidiaries in the CEE region. Central European Business Review, 4(1), p.5.

23. Sender, A., Arnold, A. and Staffelbach, B., 2017. Job security as a threatened resource: reactions to job insecurity in culturally distinct regions. The International Journal of Human Resource Management, 28(17), pp.2403-2429.

24. Sveinsdóttir, H., Ragnarsdóttir, E.D. and Blöndal, K., 2016. Praise matters: the influence of nurse unit managers' praise on nurses' practice, work environment and job satisfaction: a questionnaire study. Journal of Advanced Nursing, 72(3), pp.558-568.

25. Taber, K.S., 2018. The use of Cronbach's alpha when developing and reporting research instruments in science education. Research in Science Education, 48(6), pp.1273-1296.

26. Tao, H., Ellenbecker, C.H., Wang, Y. and Li, Y., 2015. Examining perception of job satisfaction and intention to leave among ICU nurses in China. International Journal of Nursing Sciences, 2(2), pp.140-148.

27. Thiagaraj, D. and Thangaswamy, A., 2017. Theoretical concept of job satisfaction-a study. International Journal of Research-Granthaalayah, 5(6), pp.464-470.

28. Wilczyńska, A., Batorski, D. and Sellens, J.T., 2016. Employment flexibility and job security as determinants of job satisfaction: the case of Polish knowledge workers. Social Indicators Research, 126(2), pp.633-656. 